\title{
1 Evaluation of mRNA-1273 against SARS-CoV-2 B.1.351 Infection in Nonhuman Primates
}

3 Kizzmekia S. Corbett, $\mathrm{PhD}^{1}$, Anne P. Werner, BS ${ }^{1}$, Sarah O' Connell, MS ${ }^{1}$, Matthew Gagne,

$4 \mathrm{PhD}^{1}$, Lilin Lai, $\mathrm{MD}^{2}$, Juan I. Moliva, $\mathrm{PhD}^{1}$, Barbara Flynn, $\mathrm{MS}^{1}$, Angela Choi, $\mathrm{PhD}^{3}$, Matthew

5 Koch, BS ${ }^{3}$, Kathryn E. Foulds, $\mathrm{PhD}^{1}$, Shayne F. Andrew, $\mathrm{BS}^{1}$, Dillon R. Flebbe, BS ${ }^{1}$, Evan

6 Lamb, BS ${ }^{1}$, Saule T. Nurmukhambetova, $\mathrm{MS}^{1}$, Samantha J. Provost, BS ${ }^{1}$, Kevin W. Bock, $\mathrm{MS}^{4}$,

7 Mahnaz Minai, $\mathrm{MS}^{4}$, Bianca M. Nagata, $\mathrm{MS}^{4}$, Alex Van Ry, BS ${ }^{5}$, Zackery Flinchbaugh, $\mathrm{BS}^{5}$,

8 Timothy S. Johnston, BS ${ }^{1}$, Elham Bayat Mokhtari, $\mathrm{PhD}^{1}$, Prakriti Mudvari, $\mathrm{PhD}^{1}, \mathrm{Amy} \mathrm{R}$

9 Henry, $\mathrm{MS}^{1}$, Farida Laboune, $\mathrm{MS}^{1}$, Becky Chang, $\mathrm{BS}^{5}$, Maciel Porto, BS ${ }^{5}$, Jaclyn Wear, $\mathrm{BS}^{5}$,

10 Gabriela S. Alvarado, $\mathrm{PhD}^{1}$, Seyhan Boyoglu-Barnum, $\mathrm{PhD}^{1}$, John-Paul M. Todd, BS ${ }^{1}$, Bridget

11 Bart $^{5}$, Anthony Cook, DVM ${ }^{5}$, Alan Dodson ${ }^{5}$, Laurent Pessaint, MS ${ }^{5}$, Katelyn Steingrebe ${ }^{5}$, Sayda

12 Elbashir, $\mathrm{PhD}^{3}$, Hanne Andersen, $\mathrm{PhD}^{5}$, Kai Wu, $\mathrm{PhD}^{3}$, Darin K. Edwards, $\mathrm{PhD}^{3}$, Swagata Kar,

$13 \mathrm{PhD}^{5}$, Mark G. Lewis, $\mathrm{PhD}^{5}$, Eli Bortiz, MD ${ }^{1}$, Ian N. Moore, PhD ${ }^{4}$, Andrea Carfi, $\mathrm{PhD}^{3}$, Mehul

14 S. Suthar, $\mathrm{PhD}^{2,6}$, Adrian McDermott, $\mathrm{PhD}^{1}$, Mario Roederer, $\mathrm{PhD}^{1}$, Martha C. Nason, $\mathrm{PhD}^{7}$,

15 Nancy J. Sullivan, $\mathrm{PhD}^{1}$, Daniel C. Douek, $\mathrm{MD}^{1}$, Barney S. Graham, MD ${ }^{1}$, and Robert A.

16 Seder, $\mathrm{MD}^{1} *$

$18{ }^{1}$ Vaccine Research Center; National Institute of Allergy and Infectious Diseases; National

19 Institutes of Health; Bethesda, Maryland, 20892; United States of America

$20{ }^{2}$ Center for Childhood Infections and Vaccines of Children's Healthcare of Atlanta, Department

21 of Pediatrics, Department of Microbiology and Immunology, Emory Vaccine Center, Emory

22 University, Atlanta, Georgia, 30322, United States of America

$23{ }^{3}$ Moderna Inc., Cambridge, MA, 02139; United States of America 
$24{ }^{4}$ Infectious Disease Pathogenesis Section; National Institute of Allergy and Infectious Diseases;

25 National Institutes of Health; Bethesda, Maryland, 20892; United States of America

$26 \quad{ }^{5}$ Bioqual, Inc.; Rockville, Maryland, 20850; United States of America

$27{ }^{6}$ Department of Microbiology and Immunology; Atlanta, Georgia, 30329, United States of

28 America

$29{ }^{7}$ Biostatistics Research Branch, Division of Clinical Research, National Institute of Allergy and

30 Infectious Diseases, National Institutes of Health; Bethesda, Maryland, 20892; United States of

31 America

32

$33 *$ Correspondence: rseder@mail.nih.gov and bgraham@nih.gov

34 


\section{ABSTRACT}

37 Background: Vaccine efficacy against the B.1.351 variant following mRNA-1273 vaccination

38 in humans has not been determined. Nonhuman primates (NHP) are a useful model for

39 demonstrating whether mRNA-1273 mediates protection against B.1.351.

40 Methods: Nonhuman primates received 30 or $100 \mu \mathrm{g}$ of mRNA-1273 as a prime-boost vaccine

41 at 0 and 4 weeks, a single immunization of $30 \mu \mathrm{g}$ at week 0 , or no vaccine. Antibody and $\mathrm{T}$ cell

42 responses were assessed in blood, bronchioalveolar lavages (BAL), and nasal washes. Viral

43 replication in BAL and nasal swabs were determined by qRT-PCR for sgRNA, and

44 histopathology and viral antigen quantification were performed on lung tissue post-challenge.

45 Results: Eight weeks post-boost, $100 \mu \mathrm{g}$ x2 of mRNA-1273 induced reciprocal $\mathrm{ID}_{50}$ neutralizing

46 geometric mean titers against live SARS-CoV-2 D614G and B.1.351 of 3300 and 240,

47 respectively, and 430 and 84 for the $30 \mu \mathrm{g}$ x2 group. There were no detectable neutralizing

48 antibodies against B.1351 after the single immunization of $30 \mu \mathrm{g}$. On day 2 following B.1.351

49 challenge, sgRNA in BAL was undetectable in 6 of 8 NHP that received $100 \mu \mathrm{g}$ x 2 of mRNA-

501273 , and there was a $\sim 2-\log$ reduction in sgRNA in NHP that received two doses of $30 \mu \mathrm{g}$

51 compared to controls. In nasal swabs, there was a $1-\log _{10}$ reduction observed in the $100 \mu \mathrm{g} x 2$

52 group. There was limited inflammation or viral antigen in lungs of vaccinated NHP post-

53 challenge.

\section{Conclusions:}

55 Immunization with two doses of mRNA-1273 achieves effective immunity that rapidly controls

56 lower and upper airway viral replication against the B.1.351 variant in NHP. 


\section{INTRODUCTION}

58 The severe acute respiratory syndrome coronavirus-2 (SARS-CoV-2) pandemic has led to more

59 than 3.4 million deaths worldwide ${ }^{1}$. Vaccination with two $100 \mu \mathrm{g}$ doses of mRNA-1273, a lipid

60 nanoparticle (LNP) encapsulated messenger RNA-based vaccine encoding a stabilized full-

61 length SARS-CoV-2 Wuhan-Hu-1 spike (S) glycoprotein, proved 94\% efficacious against

62 symptomatic COVID-19 in the United States (US) ${ }^{2}$. mRNA-1273 is authorized by the US Food

63 and Drug Administration for Emergency Use (EUA).

64 The emergence of SARS-CoV-2 variants of concern (VOC) ${ }^{3}$ that show reduced neutralization by

65 sera from Wu-1 strain convalescent subjects or vaccinees ${ }^{4-6}$ has created uncertainty about the

66 efficacy of current SARS-CoV-2 vaccines against VOC infection. To date, the most concerning

67 variants contain combinations of mutations and deletions in the $\mathrm{S}$ receptor-binding domain

68 (RBD) and N-terminal domain (NTD), respectively. Acquisition of amino acid substitutions in

69 the S RBD-- namely K417N, E484K, and N501Y - and in the NTD, such as L18F, D80A,

$70 \mathrm{D} 215 \mathrm{G}$, and $\Delta 242-244$, is associated with increased transmissibility and reduction in

71 neutralization sensitivity ${ }^{7-17}$. Variants containing these substitutions originally isolated in the

72 United Kingdom (UK) (B.1.1.7), Republic of South Africa (B.1.351), Brazil (P.1 lineage), New

73 York (B.1.526), and California (B.1.427/B.1.429), have shown varying reduction in

74 neutralization by convalescent and vaccine serum, and are resistant to some monoclonal

75 antibodies ${ }^{14,18-24}$. Among these variants, B.1.351 contains the most concerning set of

76 mutations in the RBD and NTD subdomains ${ }^{25}$.

77 We and others recently reported that sera from mRNA-1273-immunized human and nonhuman

78 primates (NHP) showed the greatest reduction of neutralization against B.1.351 compared to

79 B.1.1.7, P.1, B.1.427/B.1.429, and B.1.1.7+E484K variants ${ }^{7-17,26}$. In UK- or US-based clinical 
80 studies, NVX-CoV2373 (Novavax), AZD1222 (University of Oxford/AstraZeneca), and

81 Ad26.COV2.S (Janssen/Johnson \& Johnson) vaccines show between $\sim 70$ and $90 \%$ protection

82 against the circulating D614G or B.1.1.7 variants $^{11,27-29}$, and vaccine efficacy against mild

83 symptomatic COVID-19 caused by B.1.351 was up to $60 \%$ for Ad26.CoV2 $2^{29}$ and NVX-

$84 \mathrm{CoV} 2373^{30}$ and $\sim 10 \%$ for AZD122 ${ }^{31}$. A recent report showed BNT162b2, Pfizer's mRNA

85 vaccine, conferred $\sim 75 \%$ protection against confirmed B.1.351 infection in Qatar ${ }^{32}$. While

86 immunological assessments for all vaccine trials are underway and correlates of protection are

87 not yet determined, these data highlight the potential impact that reduced neutralization capacity

88 to B.1.351 may have on protection against mild symptomatic COVID-19 across various

89 platforms. Though comparable to BNT162b2 in other settings, human efficacy trials with

90 mRNA-1273 have not been conducted in regions where B.1.351 circulates as a dominant variant.

91 Vaccine development for COVID-19 has benefitted from clinically translatable data from the

$92 \mathrm{NHP}^{33-39}$. As there have been no published studies on vaccine protection in NHP challenged with

93 the B.1.351 variant, we evaluated the impact of the dose and number of immunizations with

94 mRNA-1273 on immunogenicity and protection against B.1.351 challenge in NHP.

\section{METHODS}

\section{Pre-clinical mRNA-1273 mRNA and Lipid Nanoparticle Production Process}

98 A sequence-optimized mRNA encoding prefusion-stabilized SARS-CoV-2 S-2 $\mathrm{P}^{40,41}$ protein was

99 synthesized in vitro. The mRNA was purified by oligo-dT affinity purification and encapsulated

100 in a lipid nanoparticle through a modified ethanol-drop nanoprecipitation process described

101 previously $^{42}$.

\section{Rhesus Macaque Model}


103 Animal experiments were carried out in compliance with US National Institutes of Health

104 regulations and approval from the Animal Care and Use Committee of the Vaccine Research

105 Center and Bioqual, Inc. (Rockville, MD). Challenge studies were conducted at Bioqual, Inc.

106 Male and female, 3-12 year-old, Indian-origin rhesus macaques were sorted by sex, age and

107 weight (Supplemental Appendix) and then stratified into groups of four. NHP were immunized

108 intramuscularly (IM) at week 0 and week $4-5$ with either 30 or $100 \mu \mathrm{g}$ mRNA-1273 in $1 \mathrm{~mL}$ of

109 1X PBS into the right hind leg or $30 \mu \mathrm{g}$ at week 0 . Naïve aged-matched NHP were included as

110 controls. At week 12 (7-8 weeks post-boost or 12 weeks after the single vaccination), all NHP

111 were challenged with a total dose of $5 \times 10^{5}$ PFU of SARS-CoV-2 B.1.351 strain. The viral

112 inoculum was administered as $3.75 \times 10^{5}$ PFU in $3 \mathrm{~mL}$ intratracheally (IT) and $1.25 \times 10^{5}$ PFU in 1

$113 \mathrm{~mL}$ intranasally (IN) in a volume of $0.5 \mathrm{~mL}$ into each nostril. Pre- and post-challenge sample

114 collection is detailed in Figure S1.

\section{Quantification of SARS-CoV-2 RNA and sgRNA}

116 At the time of collection, NS were frozen in $1 \mathrm{~mL}$ of $1 \mathrm{X}$ PBS containing $1 \mu \mathrm{L}$ of SUPERase-In

117 RNase Inhibitor (Invitrogen) and BAL was mixed with $1 \mathrm{~mL}$ of RNAzol BD containing $10 \mu \mathrm{L}$

118 acetic acid and both were frozen at $-80^{\circ} \mathrm{C}$ until extraction. Extraction and quantitation of $\operatorname{sgRNA}$

119 envelope (E) and nucleocapsid (N) were performed as previously described ${ }^{38}$.

\section{10-plex Meso Scale ELISA}

121 Multiplexed plates (96-well) precoated with SARS-CoV-2 S-2P $\mathrm{P}^{41}$ and RBD proteins from the

122 following strains: WA-1, B.1.351, B.1.1.7, and P.1., SARS-CoV-2 N protein, and Bovine Serum

123 Albumin (BSA) are supplied by the manufacturer [Meso Scale Display (MSD)]. Determination

124 of antibody binding was performed as previously described ${ }^{43}$.

\section{4-plex Meso Scale ELISA}


126 MSD SECTOR ${ }^{\circledR}$ plates are precoated by the manufacturer with SARS-CoV-2 proteins $\left(\mathrm{S}-2 \mathrm{P}^{41}\right.$,

127 RBD, and N) and a BSA control in each well in a specific spot-designation for each antigen.

128 Determination of antibody binding was performed as previously described ${ }^{38}$.

129 Meso Scale ELISA for Mucosal Antibody Responses

130 Using previously described methods ${ }^{44}$, total S-specific IgG and IgA were determined by

131 MULTI-ARRAY ELISA using Meso Scale technology (Meso Scale Discovery, MSD).

\section{Lentiviral Pseudovirus Neutralization Assay}

133 As previously described ${ }^{45}$, pseudotyped lentiviral reporter viruses were produced by the co-

134 transfection of plasmids encoding S proteins from Wuhan-1 strain (Genbank \#: MN908947.3)

135 with a D614G mutation, a luciferase reporter, lentivirus backbone, and human transmembrane 136 protease serine 2 (TMPRSS2) genes into HEK293T/17 cells (ATCC CRL-11268). Similarly,

137 pseudoviruses containing S from B.1.351, P.1, and B.1.1.7 were produced. Sera, in duplicate,

138 were tested for neutralizing activity against the pseudoviruses by quantification of luciferase

139 activity [in relative light units (RLU)].

140 VSV Pseudovirus Neutralization Assay

141 To make SARS-CoV-2 pseudotyped recombinant VSV- $\Delta$ G-firefly luciferase virus, BHK21/WI-

1422 cells (Kerafast, EH1011) were transfected with the Wuhan-1 strain (Genbank \#: MN908947.3)

143 S plasmid expressing full-length S with D614G mutation or S of B.1.351. Neutralization assays

144 were completed on A549-ACE2-TMPRSS2 cells with serially diluted serum samples as

145 previously described ${ }^{26}$.

146 Focus Reduction Neutralization Test (FRNT) 
147 Viruses were propagated in Vero-TMPRSS2 cells to generate viral stocks. Viral titers were

148 determined by focus-forming assay on VeroE6 cells. Viral stocks were stored at $-80^{\circ} \mathrm{C}$ until use.

149 FRNT assays were performed as previously described ${ }^{46}$.

\section{Statistical Analysis}

151 Graphs show data from individual NHP with dotted lines indicating assay limits of detection.

152 Groups were compared by Kruskal-Wallis test, followed by pairwise Wilcoxon Rank-sum tests

153 with Holm's adjustment on the set of pairwise tests if the Kruskal-Wallis was significant, for the

154 primary analysis of viral load at day 2 in the BAL and NS, as well as other comparisons between

155 dose groups. Correlations were estimated and tested using Spearman's nonparametric method.

156 Linear regression was used to explore the relationship between antibody levels and sgRNA,

157 including quadratic terms for comparing the newly generated data and that previously published

158 (ref $)^{47}$, with likelihood ratio tests to compare models and assess interaction effects.

\section{RESULTS}

\section{Humoral and mucosal antibody responses following mRNA-1273 vaccination}

162 Vaccination of NHP with 10-100 $\mu \mathrm{g}$ of mRNA-1273 at weeks 0 and 4 conferred rapid and

163 complete control of detectable viral replication in both the upper and lower airways following

164 SARS-CoV-2 USA/Washington-1 (WA-1) challenge ${ }^{33,38}$. In the current study, to assess the

165 influence of dose and number of immunizations on immunogenicity and protection against

166 B.1.351, NHP were immunized with 30 or $100 \mu \mathrm{g}$ in the standard 0 - and 4-week vaccine regimen

167 (x2) or a single dose (x1) of $30 \mu \mathrm{g}$ (Figure S1).

168 We first performed a temporal analysis of serum neutralizing antibody responses after single

169 immunization or prime and boost with mRNA-1273. Neutralizing responses of 50 and 99 
170 geometric mean reciprocal ID $_{50}$ titers $(\mathrm{GMT})$ were detected against D614G by 2 weeks after a

171 single immunization with 30 or $100 \mu \mathrm{g}$ of mRNA-1273, respectively. Consistent with our prior

172 study $^{38}$, there was a 100-fold increase in D614G-specific neutralizing antibodies following a

173 boost with 100 or $30 \mu \mathrm{g}$ of mRNA-1273. All 8 of the $100 \mu \mathrm{g}$ x 2 immunized NHP and 7 of 8

174 receiving $30 \mu \mathrm{g} \times 2$ had $>10^{3}$ reciprocal $\mathrm{ID}_{50}$ titers (Figures 1E-G and S2A) and 14/16 animals

175 from the 2-dose regimen had detectable neutralizing activity against B.1.351 (Figures 1E-G and

176 S2B). By contrast, only 6/8 NHP that received a single dose of $30 \mu \mathrm{g}$ had detectable neutralizing

177 responses against D614G (Figures 1E-G and S2A), and none (0/8) had detectable neutralizing

178 antibodies against B.1.351 (Figures 1E-G and S2B). Following boost in the 30 and $100 \mu \mathrm{g}$ x2

179 groups, neutralizing antibodies against B.1.351 remained $>10^{2}$ and $>10^{3}$ reciprocal $\mathrm{ID}_{50}$ GMT,

180 respectively (Figures 1E-G and S2B). These data support the importance of boosting to increase

181 neutralizing responses against the B.1351 variant.

182 Focusing on the time of challenge, $\sim 8$ weeks post-boost or 12 weeks after the single

183 immunization, S-specific binding and neutralizing antibody responses were assessed. Using a 10-

184 plex MULTI-ARRAY ELISA, we assessed WA-1 and B.1.351 S- and RBD- specific antibody

185 binding responses (Figure 1A-D), which represent the vaccine and challenge strains,

186 respectively. Binding to $\mathrm{S}$ and RBD proteins representing the P.1 lineage, which is prominent in

187 Brazil, and the highly transmissible B.1.1.7 variant, which is circulating globally, were also

188 assessed (Figure S3A-D). There was a vaccine dose-dependent increase in S- and RBD-specific

189 antibody responses against WA-1 (Figure 1A-B) and B.1.351 (Figure 1C-D), where, for

190 example, a single dose of $30 \mu \mathrm{g}$ of mRNA-1273 elicited 1,800 area under the curve (AUC) units

191 for B.1.351 S-specific antibody responses, and two doses of $100 \mu \mathrm{g}$ elicited 19,000 AUC. 
B.1.1.7 (Figure S3A-B). P.1 (Figure S3C-D) S- and RBD-specific responses were similarly

193 dose-dependent.

194 In vitro neutralizing activity was next determined using two orthogonal pseudovirus

195 neutralization assays and a live virus assay. Neutralizing responses against B.1.351 was

196 compared to D614G, the benchmark strain that is being used for correlates analysis of the Phase

1973 studies with mRNA-1273 and other vaccines. Using a D614G lentiviral-based pseudovirus

198 neutralization assay, the reciprocal $\mathrm{ID}_{50}$ GMT was $\sim 3,600$ following two doses of $100 \mu \mathrm{g}$.

199 Consistent with the 8-fold reduction reported by us and others using human vaccine or

200 convalescent serum $^{26,43,48-50}$, the reciprocal $\mathrm{ID}_{50}$ GMT against B.1.351 was $\sim 450$. Notably, in

201 NHP that received a single $30 \mu \mathrm{g}$ dose of mRNA, the reciprocal $\mathrm{ID}_{50}$ GMT against D614G was

$202 \sim 150$, but there were no detectable neutralizing antibodies against B.1.351 (Figure 1E). We

203 observed similar outcomes using VSV-based pseudovirus (Figure 1F) and live virus (Figure

204 1G) neutralization assays. To extend the analysis, neutralization against the B.1.1.7 and P.1

205 variants was assessed. There was little change in neutralization in any vaccine group comparing

206 D614G to B.1.1.7 (Figure S3E); however, the reduction in neutralization against the P.1 variant

207 compared to D614G was similar to that observed with B.1.351 (Figure S3F). Taking all of these

208 data together, antibody binding and neutralization responses were highly correlated with one

209 another (Figure S4).

210 To extend the antibody analyses to the mucosal sites of infection, S-specific IgG and IgA in BAL

211 and nasal wash samples were assessed at $\sim 3$ weeks post-boost or 7 weeks after the single $30 \mu \mathrm{g}$

212 immunization. Consistent with systemic humoral responses, there was a dose-dependent increase

213 in BAL and nasal wash WA-1 or B.1.351 S-specific IgG and IgA (Figure 1H-O). BAL WA-1

214 (Figure 1H) or B.1.351 (Figure 1I) S-specific IgG titers following two doses of 30 or $100 \mu \mathrm{g}$ of 
215 mRNA-1273 ranged from a GMT of $10^{4}-10^{7}$ AUC, and nasal wash WA-1 (Figure 1J) or

216 B.1.351 (Figure 1K) S-specific IgG titers ranged from $10^{2}-10^{5}$ AUC. For BAL, there was also a

217 dose-dependent trend for WA-1 (Figure 1L) or B.1.351 (Figure 1M) S-specific IgA titers, albeit

218 to lower magnitude than for IgG. mRNA-1273 did not induce notable upper airway WA-1

219 (Figure 1N) or B.1.351 (Figure 1O) S-specific IgA responses as nasal wash IgA levels in all

220 vaccine groups were similar to control NHP. Overall, mRNA-1273 vaccination elicits WA-1 and

221 B.1.351 S-specific $\operatorname{IgG}$ and $\operatorname{IgA}$ antibodies in serum and lower airways and $\operatorname{IgG}$ in the upper

222 airways as previously shown ${ }^{38}$.

223 T cell responses following mRNA-1273 vaccination

224 mRNA 1273 induces Th1, CD4 T follicular helper (Tfh) responses and CD8 T cells in NHP and

225 humans ${ }^{33,51,52}$. Consistent with these data, S-specific Th1 responses were induced in a dose-

226 dependent manner with higher responses in the $100 \mu \mathrm{g}$ dose group (Figure 2A). There were low

227 to undetectable Th2 responses in all vaccine groups (Figure 2B). There was also dose-

228 dependence in the frequency of S-specific Tfh responses expressing the surface marker CD40L

229 (Figure 2C) or the canonical cytokine IL-21 (Figure 2D), which are critical for improving

230 antibody responses. S-specific CD8 T cell responses were observed in 5/8 NHP that received two

231 doses of $100 \mu \mathrm{g}$ mRNA-1273 (Figure 2E). These data show that mRNA-1273 induces Th1- and

232 Tfh-skewed CD4 responses and CD8 T cells at the highest dose.

\section{Protective Efficacy against SARS-CoV-2 Replication in Upper and Lower Airways}

234 As this is the first study to challenge NHP with B.1.351, an extensive analysis was performed to

235 characterize the sequence and in vivo pathogenicity. Deep sequencing was performed after each

236 passage (P) of the B.1.351 strain, which was first isolated at Johns Hopkins University (JHU). P1

237 and P2 stocks were compared to the B.1.351 reference strain and the original JHU clinical isolate 
and retained all mutations in the RBD and NTD sites on the spike protein (Figure S5A). The

239 JHU B.1.351 P2 stock was then administered to Golden Syrian hamsters, a highly pathogenic

240 SARS-CoV-2 animal model, at three different concentrations to characterize weight loss (Figure

241 S5B) and in NHP to measure upper and lower airway viral replication by qRT-PCR for sgRNA

242 (Figures S5C-D). Based on these data, a B.1.351 challenge dose of $5 \times 10^{5}$ PFU was selected for

243 the vaccine study; this dose would induce sgRNA levels similar to the higher values obtained

244 from nasal secretions of humans following SARS-CoV-2 infection ${ }^{53,54}$.

245 To assess protective efficacy of mRNA-1273 against the B.1.351 SARS-CoV-2 variant, the NHP

246 were challenged with a total dose of $5 \times 10^{5}$ PFU of B.1.351 by intratracheal (IT) and intranasal

247 (IN) routes 7-8 weeks post-boost for the two-dose regimens and 12 weeks after the single dose

248 regimen (Figure S1). Two days post-challenge, only 2 of 8 NHP that received $100 \mu \mathrm{g}$ of mRNA-

2491273 had detectable SARS-CoV-2 envelope (E) sgRNA (sgRNA_E) in BAL compared to 8 of 8

250 in the control group (Figure 3A). By sgRNA_E (Figure 3A) or nucleocapsid (N) sgRNA

251 (sgRNA_N) qRT-PCR (Figure 3C), the $100 \mu \mathrm{g}$ group had a significant decrease in viral load

252 compared to NHP that received a single dose of $30 \mu \mathrm{g}(p=0.0054)$ or to the control NHP $(p=$

253 0.0009). NHP that received $30 \mu \mathrm{g}$ x2 also had a significant decrease in viral load compared to

254 control NHP $(p=0.0054)$ and showed a trend toward reduced viral replication compared to a

255 single immunization with $30 \mu \mathrm{g}$. NHP that received a single vaccination with $30 \mu \mathrm{g}$ showed a

256 trend toward reduced viral replication compared to control NHP. At day 4 post-challenge, the

257 pattern was the same, with significant reduction in viral replication in BAL for all vaccine groups

258 compared to control NHP, and for the $100 \mu \mathrm{g}$ group compared to $30 \mu \mathrm{g}$ x1 (Figures 3A,C). By

259 day 7 , while 7 of 8 control NHP still had $~ 4 \operatorname{logs}$ of sgRNA_E, there was no detectable

260 sgRNA_E in 6 of 8 NHP in all vaccine groups (Figure 3A), consistent with control of viral 
261 replication in the lower airway. In addition, the inability to culture virus from the BAL of 4/8 and

$2627 / 8$ NHP immunized with 30 and $100 \mu \mathrm{g}$ x2 of mRNA-1273, respectively, two days post-

263 challenge further confirms the ability of mRNA-1273 to control lower airway viral replication

264 (Figure 3E). Moreover, on day 2 post-challenge, BAL viral titers and sgRNA were highly

265 correlated (Figures 3F-G), where no virus was culturable from BAL of all NHP with BAL

266 sgRNA_N $<1.2 \times 10^{4}$ RNA copies/mL (Figure 3G).

267 In contrast to the significant reduction of viral replication in the lower airway, at day 2 post-

268 challenge, the only significant reduction in viral replication for sgRNA_E (Figure 3B) or sgRNA

$269 \_\mathrm{N}$ (Figure 3D) in nasal swabs (NS) was in the $100 \mu \mathrm{g}$ dose group. The differences in NHP that

270 received $100 \mu \mathrm{g} \mathrm{x} 2$ were marginally lower compared to the groups that received $30 \mu \mathrm{g}$ x 2 or 30

$271 \mu \mathrm{g} \mathrm{x1}(p=0.0273$ and 0.0350 , respectively) with no other significant pairwise differences. The

272 groups were not significantly different at the later time points. A notable finding was that 5 of 8

273 control NHP still had $\sim 4 \log _{10}$ of sgRNA_E and all 8 NHP had sgRNA_N at day 7 in the NS,

274 highlighting persistence of sgRNA following B.1.351 through day 7 post-challenge. With that,

275 there was $\sim 4 \log _{10}$ of sgRNA_E in the NS of 3 of 8 NHP in the $100 \mu \mathrm{g}$ x 2 group. Overall, these

276 data show significant reduction and rapid control of B.1.351 viral replication in the lower

277 airways of mRNA-1273 immunized NHP with more limited control in the upper airway.

\section{Inflammation and viral load in lung tissue post-challenge}

279 To provide a further assessment of protection following vaccination, NHP in each of the dose

280 groups were assessed for virus-related pathology and for the detection of viral antigen (VAg) in

281 the lung 8 days post B.1.351 challenge. The severity of inflammation, which ranged from

282 minimal to moderate, was similar across lung samples from NHP that received vaccine in doses

283 of $100 \mu \mathrm{g}$ x2, $30 \mu \mathrm{g}$ x2, or $30 \mu \mathrm{g}$ x1 (Figure S6). The inflammatory lesions in the lung were 
284 characterized by a mixture of lymphocytes, histiocytes and fewer polymorphonuclear cells

285 associated with variably expanded alveolar capillaries, occasional areas of perivascular

286 inflammation, and Type II pneumocyte hyperplasia. Two out of 4 NHP that received $30 \mu \mathrm{g}$ x1 of

287 mRNA-1273 vaccine had trace amounts of virus detected in the lung. There was no detection of

288 VAg in any lung sample from NHP that received two doses of 30 or $100 \mu \mathrm{g}$. All 4 NHP in the

289 control group had variable amounts of VAg detected in the lung (Figure S6, Table S1).

\section{Post-challenge humoral and mucosal antibody responses}

291 The assessment of antibody responses post-challenge has been useful for determining whether

292 viral replication in the BAL or NS is sufficient to boost vaccine-induced anamnestic S-specific

293 antibody responses in these mucosal tissues ${ }^{38,44}$. In BAL, WA-1 and B.1351 S-specific IgG

294 (Figures S7A-B) or IgA (Figures S7C-D) responses did not increase post-challenge in NHP that

295 received two immunizations of 30 or $100 \mu \mathrm{g}$ of mRNA-1273. However, by 14 days post-

296 challenge, there was an increase in WA-1 and B.1.351 S-specific IgG responses in NHP that

297 received $30 \mu \mathrm{g} \times 1$ of mRNA-1273, to levels that were similar to the NHP that received 30 or 100

$298 \mu \mathrm{g}$ x2 and higher than the unvaccinated controls (Figures S7A-D). In NS, there was an increase

299 in WA-1 and B.1.351 S-specific IgG (Figures S7E-F) or IgA (Figures S7G-H) responses in

300 unvaccinated NHP and those immunized with $30 \mu \mathrm{g}$ of mRNA-1273 once or twice; however,

301 there were no anamnestic S-specific antibody responses in $100 \mu \mathrm{g}$ dose group. Overall, these

302 data show that the increase in S-specific anamnestic antibody responses in both the BAL and NS

303 are associated with viral replication in these mucosal sites and may explain the relatively rapid

304 clearance of virus from NS in the $30 \mu \mathrm{g} \times 1$ dose group.

\section{Antibody correlates of protection}


Assessing immune correlates of protection following vaccination is a critical aspect of vaccine development. We recently reported that mRNA-1273 induced antibody responses are a mechanistic correlate for reducing viral replication against WA-1 challenge in NHP ${ }^{38}$. Here, B.1.351 S-specific IgG antibody titers at week 12, the time of challenge, also correlated strongly with reduction of sgRNA in both BAL (Figure 4A) and NS (Figure 4D) at day 2 post-challenge.

311 In addition, both pseudovirus and live viral neutralization correlate significantly with reduction 312 of sgRNA in both BAL (Figure 4B-C) and NS (Figures 4E-F).

313 In a recent report on correlates of protection following mRNA-1273 immunization in NHP, we

314 established a linear relationship between WA-1 S-specific antibody titers as defined by

315 international units (IU) and subsequent sgRNA 2 days after SARS-CoV-2 WA-1 challenge.

316 Here, we similarly converted pre-challenge WA-1 S-specific antibody titers to IU (Table S2).

317 Again, pre-challenge WA-1 S-specific IgG titers and sgRNA in BAL (Figure 4G) and NS

318 (Figure 4H) at day 2 post-challenge were negatively correlated. Based on a linear model,

319 vaccinated animals that had S-specific IgG of 100 and $120 \mathrm{IU} / \mathrm{mL}$ were predicted to have

320 sgRNA_N and sgRNA_E, respectively, in BAL of approximately $2 \log _{10}$ lower than the average

321 for PBS controls. Serum neutralizing activity was associated with control of viral replication;

$32213 / 14$ of the NHP with detectable pseudovirus neutralizing activity against B.1.351 had BAL

323 sgRNA_N $<10^{5}$ (Figure 4B). A similar linear relationship between S-specific antibody levels

324 and viral replication in nasal swabs was apparent, although few of the NHP had NS sgRNA_N

325 below $10^{5}$.

326 As the antibody levels of S-specific IgG are very similar to those we had previously reported

327 using NHP challenged with the SARS-CoV-2 WA-1 ${ }^{38}$, we conducted an additional exploratory

328 analysis of the data from both studies to investigate the consistency of the relationship between 
329 S-specific antibodies and BAL sgRNA, across the two different viruses. For low S-specific IgG

330 levels, sgRNA was higher for animals challenged with B.1.351, but for animals with levels of S-

331 specific IgG greater than approximately $100 \mathrm{IU} / \mathrm{mL}$, the estimated regression curve slopes are

332 similar as are the levels that correspond to $2-4 \log _{10}$ reductions in $\operatorname{sgRNA}$ in BAL compared to

333 controls (Figure 4I). These data suggest a similar relationship between S-specific IgG levels and

334 lower airway protection against homologous and variant SARS-CoV-2 strains in NHP.

\section{DISCUSSION}

337 mRNA-1273 and BNT162b2 vaccines were shown to be $\sim 95 \%$ effective in clinical trials

338 performed in the US, during which times WA-1 and D614G variants circulated most widely ${ }^{2,55}$.

339 A critical issue is whether these and other vaccines will mediate protection against the rapidly

340 emerging variants. At present, the B.1.351 variant is one of greatest concern compared to WA-1,

341 D614G, or B.1.1.7 based on the higher reduction in neutralization using vaccine sera ${ }^{7-17}$ and

342 clinical trials showing lower efficacy against mild infection ${ }^{29-31}$. Here, we present evidence that

343 mRNA-1273 can significantly reduce viral replication in the upper and lower airways and

344 prevent or limit inflammation in the lung following B.1.351 challenge in NHP. Importantly, the

345 dose of the vaccine and number of immunizations had a significant effect on the protective

346 capacity. These data are consistent with a recent report showing that vaccine effectiveness

347 against PCR-confirmed infection with the B.1.351 variant is $16 \%$ after 1 dose of BNT162b2 and $348 \quad 75 \%$ after two doses ${ }^{32}$.

349 Antibodies play a critical role in mediating vaccine-elicited protection against SARS-CoV-2 in

350 NHP models ${ }^{33,37,39,44,56,57}$. Here, we show that there was a dose-dependent increase in WA-1 and 
351 B.1.351 S- and RBD-specific antibody titers and D614G and B.1.351 neutralization titers

352 (Figure 1A-D). Of note, there was $\sim 5-10$-fold reduction in sensitivity to neutralization for

353 B.1.351 compared to D614G, consistent with many reports assessing responses from humans

354 that received mRNA 1273 or other vaccines. There was also a dose-dependent increase in WA-1

355 and B.1351 S-specific IgG in BAL and nasal washes, where IgA was detected only in the $100 \mu \mathrm{g}$

356 group. Importantly, while there were detectable neutralization titers against D614G following a

357 single immunization with $30 \mu \mathrm{g}$, these NHP had no detectable neutralization against B.1.351. By

358 contrast, neutralizing titers against B.1.351 following a second immunization with 30 or $100 \mu \mathrm{g}$

359 increased to $\sim 10^{3}$ reciprocal $\mathrm{ID}_{50}$ titer. These data highlight the importance of a prime and boost

360 regimen for optimizing neutralization antibody responses, particularly against B.1.351 and likely

361 for any other variant of concern for which vaccine-induced neutralization is decreased. Last, the

362 frequency of S-specific Th1 and Tfh responses were also dose-dependent, with CD8 T cell

363 responses detected in blood only in NHP receiving the $100 \mu \mathrm{g}$ dose. These data corroborate

364 previous studies by us and others that have shown a direct correlation between CD4 T cell

365 responses, most notably Tfh cells, and improved magnitude and function of antibody responses

366 in $\mathrm{NHP}^{33,38,51,58}$.

367 As this was the first study to use the B.1.351 variant for challenge in NHP, extensive sequence

368 analyses were performed to propagate a challenge stock with a matched S sequence as compared

369 to the reference isolate ${ }^{59}$. Naïve NHP infected with the B.1.351 stock notably had peak sgRNA

370 levels of $\sim 10^{7}$ copies/mL in BAL, which is higher than reported by us and others for challenge

371 studies using the WA-1 strain $^{33,37,39,44,56,57}$. At 7 days post-challenge, most of the control NHP

372 still had $\sim 10^{5}$ RNA copies/mL and copies/swab present in BAL and NS, respectively. This

373 contrasts with the more rapid and complete reduction of viral replication following challenge 
374 with the WA-1 strain $^{33,37,39,44,56,57}$ and higher than viral load typically seen in human infections.

375 Whether the amount and persistence of the B.1351 virus in vivo in this study relates to the

376 challenge dose or suggests that this variant has inherent properties that make it more difficult to

377 control and clear compared to the WA-1 strain is a focus of ongoing analyses.

378 The dose of B.1351 used here provided a stringent challenge for vaccine-elicited protection.

379 Nonetheless, there was a significant reduction in viral replication in BAL at day 2 post-challenge

380 in the groups that received 30 and $100 \mu \mathrm{g}$ twice; 6 of 8 NHP that received the clinically relevant

$381100 \mu \mathrm{g}$ vaccine regimen had no detectable sgRNA_E in BAL. Of note, while there was no

382 detectable serum neutralizing activity against B.1351 virus with a single immunization of $30 \mu \mathrm{g}$,

383 there was still significant reduction in viral replication in BAL by day 4 post-challenge compared

384 to controls with limited inflammation or viral antigen in the lungs at day 7 . These data are

385 consistent with our recent study in which NHP immunized with only 1 or $3 \mu \mathrm{g}$ of mRNA-1273

386 twice demonstrated a reduction in viral replication in BAL and limited lung pathology following

387 WA-1 challenge despite absence of detectable neutralizing activity ${ }^{38}$. There are several potential

388 mechanisms for lower airway protection in the absence of detectable serum neutralizing

389 antibodies. First, binding antibodies could mediate viral reduction through various Fc effector

390 functions in the BAL as has been suggested as a mechanism for protection from vaccine-induced

391 polyclonal serum ${ }^{60,61}$ and certain monoclonal antibodies ${ }^{62,63}$. Second, vaccine-primed anamnestic

392 responses in the BAL in the first week post-challenge may enhance control of infection ${ }^{38,44}$.

393 Third, current in vitro assays may not be sensitive enough to detect the full spectrum of in vivo

394 neutralization activity, that may be present in vivo. Last, while it is possible that $\mathrm{T}$ cells are

395 contributing to control of viral replication in the lower airway, there is no current evidence for

396 this following vaccination or primary infection ${ }^{64}$ in the NHP model. 
397 In contrast to protection observed in the lower airway against the B.1.351 challenge, there was

398 more limited control of viral replication in the upper airway except in NHP that received 2 doses

399 of $100 \mu \mathrm{g}$. These data are consistent with prior studies in NHP showing that a higher amount of

400 antibody is required for reduction of viral replication in the upper airway than the lower airway

401 following mRNA-1273 vaccination ${ }^{33,38}$. Moreover, recent results from human vaccine trials

402 show that there is greater protection against severe disease than mild disease against the B.1.351

403 variant following immunization with Ad26.CoV2 $2^{29}$ or BNT162b2 $2^{32}$.

404 Serum antibody levels were strong predictors of reduction of viral load in BAL and NS. These

405 data are consistent with studies by us and others showing that antibodies can be a mechanistic

406 correlate of protection in NHP following vaccination ${ }^{38}$ or infection $^{64}$. The correlation is most

407 robust between S-specific IgG and BAL sgRNA; our modeling suggests that animals with S-

408 specific IgG levels of approximately $100 \mathrm{IU} / \mathrm{mL}$ display sgRNA levels in BAL of approximately

$4092 \log _{10}$ lower than the control animals, with a further decrease of approximately $2 \log _{10} \operatorname{sgRNA}$

410 for every $1 \log _{10}$ increase in IgG IU/mL. We also noted that $13 / 14$ animals with any detectable

411 neutralizing antibodies against B.1.351 had BAL sgRNA_N $<10^{5}$. Note that no virus was

412 culturable from BAL of any NHP with BAL sgRNA_N $<1.2 \times 10^{4}$ RNA copies/mL. These data

413 suggest that even for vaccines that elicit low to undetectable B.1.351-specific neutralizing

414 antibodies, there can still be control of viral replication in the lower airway.

415 The NHP model has been critical for guiding vaccine development against COVID-19 in

416 humans. This report provides evidence that the current two-dose regimen with mRNA-1273 is

417 important for inducing higher neutralizing antibody responses, CD4 and CD8 T cell immunity

418 and protection from viral replication in the lower and upper airways. The durability of immune

419 responses and protection will likely be related to maintaining a combination of serum antibody 
420 and memory B cells that can rapidly respond to a new virus exposure. Moreover, immunity

421 against B.1.351 or other variants of concern can be assessed by comparing reduction in

422 neutralizing activity relative to $\mathrm{D} 614 \mathrm{G}$ over time ${ }^{43}$. Ongoing studies are assessing how additional

423 boosting with spike antigens based on WA-1 or variant strains will influence immunity and

424 protection against B.1351 and other emerging variants in this model and in humans.

426 Acknowledgements

427 We thank any additional members of all included laboratories for critical discussions and advice

428 pertaining to experiments included in the manuscript. We thank Judy Stein and Monique Young

429 for technology transfer and administrative support, respectively. We thank members of the NIH

430 NIAID VRC Translational Research Program, including Chris Case, Hana Bao, Elizabeth

431 McCarthy, Jay Noor, Alida Taylor, and Ruth Woodward, for technical and administrative

432 assistance with animal experiments. We thank Huihui Mu and Michael Farzan for the ACE2-

433 overexpressing 293 cells. We thank Adrian Creanga and Masaru Kanekiyo for the Vero-

434 TMPRSS2 cells. We thank the laboratory of Peter Kwong for providing protein for use in ELISA

435 assays for detection of mucosal antibodies. We thank Andy Pekosz for the B.1.351 variant. We

436 thank Michael Brunner and Michael Whitt for kind support on recombinant VSV-based SARS-

437 CoV-2 pseudovirus production. This work was supported by the Intramural Research Program of

438 the VRC, NIAID, NIH. mRNA-1273 has been funded in part with Federal funds from the

439 Department of Health and Human Services, Office of the Assistant Secretary for Preparedness

440 and Response, Biomedical Advanced Research and Development Authority, under Contract

441 75A50120C00034. K.S.C.'s research fellowship was partially funded by the Undergraduate

442 Scholarship Program, Office of Intramural Training and Education, Office of the Director, NIH. 
443 Virus propagation and live virus neutralization assays were funded by Emory Executive Vice

444 President for Health Affairs Synergy Fund Award, Pediatric Research Alliance Center for

445 Childhood Infections and Vaccines and Children's Healthcare of Atlanta, and Woodruff Health

446 Sciences Center 2020 COVID-19 CURE Award.

448 Author Contributions

449 K.S.C., A.P.W., S.O., M.G., L.L., J.I.M., B.F., A.C., M.K, K.E.F., S.F.A., D.R.F., E. L., S.T.N.,

450 S.J.P., K.W.B., M.M., B.M.N., A.V.R., Z.F., T.S.J., E.B.M., P.M., A.R.H., F.L., B.C., M.P.,

451 J.W., J.M.T., B.B., A.C., A.D., L.P., K.S., S.E., H.A., K.W., D.K.E., S.K., M.G.L., E.B., I.N.M.,

452 A.C., M.S.S., A.M., M.R., M.C.N., N.J.S., D.C.D., B.S.G., and R.A.S. designed, completed,

453 and/or analyzed experiments. S.B-B. provided critical published reagents/analytic tools. K.S.C.,

454 M.C.N., and R.A.S wrote the manuscript. K.S.C., G.A., and M.C.N. prepared figures and tables.

455 All authors contributed to discussions in regard to and editing of the manuscript.

\section{Competing Interest Declaration}

458 K.S.C. and B.S.G. are inventors on U.S. Patent No. 10,960,070 B2 and International Patent

459 Application No. WO/2018/081318 entitled "Prefusion Coronavirus Spike Proteins and Their

460 Use.” K.S.C. and B.S.G. are inventors on US Patent Application No. 62/972,886 entitled "2019-

461 nCoV Vaccine". 
1. Dong E, Du H, Gardner L. An interactive web-based dashboard to track COVID-19 in real time. The Lancet Infectious Diseases 2020;20(5):533-534. DOI: https://doi.org/10.1016/S1473-3099(20)30120-1.

2. Baden LR, El Sahly HM, Essink B, et al. Efficacy and Safety of the mRNA-1273 SARS-CoV-2 Vaccine. New England Journal of Medicine 2020;384(5):403-416. DOI: 10.1056/NEJMoa2035389.

3. Mascola JR, Graham BS, Fauci AS. SARS-CoV-2 Viral Variants-Tackling a Moving Target. JAMA 2021;325(13):1261-1262. DOI: 10.1001/jama.2021.2088.

4. Supasa P, Zhou D, Dejnirattisai $W$, et al. Reduced neutralization of SARS-CoV-2 B.1.1.7 variant by convalescent and vaccine sera. Cell 2021;184(8):2201-2211.e7. DOI: https://doi.org/10.1016/i.cell.2021.02.033.

5. Chen RE, Zhang X, Case JB, et al. Resistance of SARS-CoV-2 variants to neutralization by monoclonal and serum-derived polyclonal antibodies. Nat Med 2021;27(4):717-726. DOI: 10.1038/s41591-021-01294-w.

6. Edara V-V, Lai L, Sahoo MK, et al. Infection and vaccine-induced neutralizing antibody responses to the SARS-CoV-2 B.1.617.1 variant. bioRxiv 2021:2021.05.09.443299. DOI: 10.1101/2021.05.09.443299.

7. Li Q, Wu J, Nie J, et al. The Impact of Mutations in SARS-CoV-2 Spike on Viral Infectivity and Antigenicity. Cell 2020;182(5):1284-1294 e9. DOI: 10.1016/j.cell.2020.07.012.

8. Tegally $\mathrm{H}$, Wilkinson $\mathrm{E}$, Giovanetti $\mathrm{M}$, et al. Detection of a SARS-CoV-2 variant of concern in South Africa. Nature 2021. DOI: 10.1038/s41586-021-03402-9.

9. Shen X, Tang H, McDanal C, et al. SARS-CoV-2 variant B.1.1.7 is susceptible to neutralizing antibodies elicited by ancestral spike vaccines. Cell Host Microbe 2021. DOI: 10.1016/j.chom.2021.03.002.

10. Wibmer CK, Ayres F, Hermanus T, et al. SARS-CoV-2 501Y.V2 escapes neutralization by South African COVID-19 donor plasma. Nat Med 2021. DOI: 10.1038/s41591-021-01285$\mathrm{x}$.

11. Voysey M, Clemens SAC, Madhi SA, et al. Safety and efficacy of the ChAdOx1 nCoV-19 vaccine (AZD1222) against SARS-CoV-2: an interim analysis of four randomised controlled trials in Brazil, South Africa, and the UK. Lancet 2021;397(10269):99-111. DOI: 10.1016/S0140-6736(20)32661-1.

12. Voysey M, Costa Clemens SA, Madhi SA, et al. Single-dose administration and the influence of the timing of the booster dose on immunogenicity and efficacy of ChAdOx1 nCoV-19 (AZD1222) vaccine: a pooled analysis of four randomised trials. Lancet 2021;397(10277):881-891. DOI: 10.1016/S0140-6736(21)00432-3.

13. Andreano $E$, Piccini $G$, Licastro $D$, et al. SARS-CoV-2 escape in vitro from a highly neutralizing COVID-19 convalescent plasma. bioRxiv 2020. DOI: 10.1101/2020.12.28.424451.

14. Hoffmann M, Arora P, Gross R, et al. SARS-CoV-2 variants B.1.351 and P.1 escape from neutralizing antibodies. Cell 2021. DOI: 10.1016/j.cell.2021.03.036. 
15. Garcia-Beltran WF, Lam EC, St Denis K, et al. Multiple SARS-CoV-2 variants escape neutralization by vaccine-induced humoral immunity. Cell 2021. DOI: 10.1016/j.cell.2021.03.013.

16. Starr TN, Greaney AJ, Hilton SK, et al. Deep Mutational Scanning of SARS-CoV-2 Receptor Binding Domain Reveals Constraints on Folding and ACE2 Binding. Cell 2020;182(5):1295-1310 e20. DOI: 10.1016/j.cell.2020.08.012.

17. Starr TN, Greaney AJ, Hilton SK, et al. Deep mutational scanning of SARS-CoV-2 receptor binding domain reveals constraints on folding and ACE2 binding. bioRxiv 2020. DOI: 10.1101/2020.06.17.157982.

18. Tada T, Dcosta BM, Zhou H, Vaill A, Kazmierski W, Landau NR. Decreased neutralization of SARS-CoV-2 global variants by therapeutic anti-spike protein monoclonal antibodies. bioRxiv 2021. DOI: 10.1101/2021.02.18.431897.

19. Tada T, Dcosta BM, Samanovic-Golden M, et al. Neutralization of viruses with European, South African, and United States SARS-CoV-2 variant spike proteins by convalescent sera and BNT162b2 mRNA vaccine-elicited antibodies. bioRxiv 2021. DOI: 10.1101/2021.02.05.430003.

20. Deng X, Garcia-Knight MA, Khalid MM, et al. Transmission, infectivity, and antibody neutralization of an emerging SARS-CoV-2 variant in California carrying a L452R spike protein mutation. medRxiv 2021. DOI: 10.1101/2021.03.07.21252647.

21. Greaney AJ, Loes AN, Crawford KHD, et al. Comprehensive mapping of mutations in the SARS-CoV-2 receptor-binding domain that affect recognition by polyclonal human plasma antibodies. Cell Host Microbe 2021;29(3):463-476 e6. DOI: 10.1016/j.chom.2021.02.003.

22. McCallum $M$, De Marco A, Lempp FA, et al. N-terminal domain antigenic mapping reveals a site of vulnerability for SARS-CoV-2. Cell 2021. DOI: 10.1016/j.cell.2021.03.028.

23. Wang P, Nair MS, Liu L, et al. Antibody resistance of SARS-CoV-2 variants B.1.351 and B.1.1.7. Nature 2021. DOI: 10.1038/s41586-021-03398-2.

24. Zhou H, Dcosta BM, Samanovic MI, Mulligan MJ, Landau NR, Tada T. B.1.526 SARS-CoV-2 variants identified in New York City are neutralized by vaccine-elicited and therapeutic monoclonal antibodies. bioRxiv 2021. DOI: 10.1101/2021.03.24.436620.

25. Tegally $H$, Wilkinson $E$, Giovanetti $M$, et al. Emergence and rapid spread of a new severe acute respiratory syndrome-related coronavirus 2 (SARS-CoV-2) lineage with multiple spike mutations in South Africa. medRxiv 2020:2020.12.21.20248640. DOI: 10.1101/2020.12.21.20248640.

26. Wu K, Werner AP, Koch M, et al. Serum Neutralizing Activity Elicited by mRNA-1273 Vaccine. New England Journal of Medicine 2021;384(15):1468-1470. DOI: 10.1056/NEJMc2102179.

27. Novavax (2021). Novavax COVID-19 Vaccine Demonstrates 89.3\% Efficacy in UK Phase 3 Trial. Press Release January 28, 2021: https://ir.novavax.com/node/15506/pdf

28. K E, Golubchik T, Aley PK, et al. Efficacy of ChAdOx1 nCoV-19 (AZD1222) vaccineagainst SARS-CoV-2 variant of concern 202012/01(B.1.1.7): an exploratory analysis of a randomisedcontrolled trial. Lancet 2021. DOI: 10.1016/S0140-6736(21)00628-0. 
550 29. Sadoff J, Gray G, Vandebosch A, et al. Safety and Efficacy of Single-Dose Ad26.COV2.S

30. Shinde V, Bhikha S, Hoosain Z, et al. Efficacy of NVX-CoV2373 Covid-19 Vaccine against the B.1.351 Variant. New England Journal of Medicine 2021;384(20):1899-1909. DOI: 10.1056/NEJMoa2103055.

31. Madhi SA, Baillie V, Cutland CL, et al. Efficacy of the ChAdOx1 nCoV-19 Covid-19 Vaccine against the B.1.351 Variant. New England Journal of Medicine 2021;384(20):1885-1898. DOI: 10.1056/NEJMoa2102214.

32. Abu-Raddad $\amalg$, Chemaitelly H, Butt AA. Effectiveness of the BNT162b2 Covid-19 Vaccine against the B.1.1.7 and B.1.351 Variants. New England Journal of Medicine 2021. DOI: 10.1056/NEJMc2104974.

33. Corbett KS, Flynn B, Foulds KE, et al. Evaluation of the mRNA-1273 Vaccine against SARSCoV-2 in Nonhuman Primates. New England Journal of Medicine 2020;383(16):15441555. DOI: 10.1056/NEJMoa2024671.

34. Guebre-Xabier M, Patel N, Tian J-H, et al. NVX-CoV2373 vaccine protects cynomolgus macaque upper and lower airways against SARS-CoV-2 challenge. Vaccine 2020;38(50):7892-7896. (In eng). DOI: 10.1016/j.vaccine.2020.10.064.

35. Mercado NB, Zahn R, Wegmann F, et al. Single-shot Ad26 vaccine protects against SARSCoV-2 in rhesus macaques. Nature 2020;586(7830):583-588. DOI: 10.1038/s41586-0202607-z.

36. van Doremalen $\mathrm{N}$, Lambe $\mathrm{T}$, Spencer A, et al. ChAdOx1 nCoV-19 vaccination prevents SARS-CoV-2 pneumonia in rhesus macaques. bioRxiv : the preprint server for biology 2020:2020.05.13.093195. (In eng). DOI: 10.1101/2020.05.13.093195.

37. $\mathrm{Yu} \mathrm{J}$, Tostanoski LH, Peter $\mathrm{L}$, et al. DNA vaccine protection against SARS-CoV-2 in rhesus macaques. Science 2020;369(6505):806. DOI: 10.1126/science.abc6284.

38. Corbett KS, Nason MC, Flach B, et al. Immune Correlates of Protection by mRNA-1273 Immunization against SARS-CoV-2 Infection in Nonhuman Primates. bioRxiv 2021:2021.04.20.440647. DOI: 10.1101/2021.04.20.440647.

39. Klasse PJ, Nixon DF, Moore JP. Immunogenicity of clinically relevant SARS-CoV-2 vaccines in nonhuman primates and humans. Science Advances 2021;7(12):eabe8065. DOI: $10.1126 /$ sciadv.abe8065.

40. Pallesen J, Wang N, Corbett KS, et al. Immunogenicity and structures of a rationally designed prefusion MERS-CoV spike antigen. Proceedings of the National Academy of Sciences 2017;114(35):E7348-E7357. DOI: 10.1073/pnas.1707304114.

41. Wrapp D, Wang N, Corbett KS, et al. Cryo-EM structure of the 2019-nCoV spike in the prefusion conformation. Science 2020;367(6483):1260-1263. DOI: 10.1126/science.abb2507.

42. Hassett KJ, Benenato KE, Jacquinet E, et al. Optimization of Lipid Nanoparticles for Intramuscular Administration of mRNA Vaccines. Molecular Therapy - Nucleic Acids 2019;15:1-11. DOI: 10.1016/j.omtn.2019.01.013.

43. Pegu A, O'Connell S, Schmidt SD, et al. Durability of mRNA-1273-induced antibodies against SARS-CoV-2 variants. bioRxiv 2021:2021.05.13.444010. DOI: 10.1101/2021.05.13.444010. 
44. Francica JR, Flynn BJ, Foulds KE, et al. Vaccination with SARS-CoV-2 Spike Protein and ASO3 Adjuvant Induces Rapid Anamnestic Antibodies in the Lung and Protects Against Virus Challenge in Nonhuman Primates. bioRxiv 2021:2021.03.02.433390. DOI: 10.1101/2021.03.02.433390.

45. Jackson LA, Anderson EJ, Rouphael NG, et al. An mRNA Vaccine against SARS-CoV-2 Preliminary Report. N Engl J Med 2020;383(20):1920-1931. (In eng). DOI: 10.1056/NEJMoa2022483.

46. Vanderheiden A, Edara VV, Floyd K, et al. Development of a Rapid Focus Reduction Neutralization Test Assay for Measuring SARS-CoV-2 Neutralizing Antibodies. Curr Protoc Immunol 2020;131(1):e116. DOI: 10.1002/cpim.116.

47. Finak G, McDavid A, Chattopadhyay $P$, et al. Mixture models for single-cell assays with applications to vaccine studies. Biostatistics 2013;15(1):87-101. DOI: 10.1093/biostatistics/kxt024.

48. Shen X, Tang H, Pajon R, et al. Neutralization of SARS-CoV-2 Variants B.1.429 and B.1.351. New England Journal of Medicine 2021. DOI: 10.1056/NEJMc2103740.

49. Edara VV, Norwood C, Floyd K, et al. Infection- and vaccine-induced antibody binding and neutralization of the B.1.351 SARS-CoV-2 variant. Cell Host \& Microbe 2021;29(4):516-521.e3. DOI: https://doi.org/10.1016/j.chom.2021.03.009.

50. Planas D, Bruel T, Grzelak L, et al. Sensitivity of infectious SARS-CoV-2 B.1.1.7 and B.1.351 variants to neutralizing antibodies. Nat Med 2021. DOI: 10.1038/s41591-02101318-5.

51. Pardi N, Hogan MJ, Naradikian MS, et al. Nucleoside-modified mRNA vaccines induce potent $T$ follicular helper and germinal center $B$ cell responses. The Journal of experimental medicine 2018;215(6):1571-1588. (In eng). DOI: 10.1084/jem.20171450.

52. Corbett KS, Edwards D, Leist SR, et al. SARS-CoV-2 mRNA Vaccine Development Enabled by Prototype Pathogen Preparedness. bioRxiv 2020.

53. Zou L, Ruan F, Huang M, et al. SARS-CoV-2 Viral Load in Upper Respiratory Specimens of Infected Patients. New England Journal of Medicine 2020;382(12):1177-1179. DOI: 10.1056/NEJMc2001737.

54. Wölfel R, Corman VM, Guggemos W, et al. Virological assessment of hospitalized patients with COVID-2019. Nature 2020;581(7809):465-469. DOI: 10.1038/s41586-0202196-x.

55. Polack FP, Thomas SJ, Kitchin N, et al. Safety and Efficacy of the BNT162b2 mRNA Covid19 Vaccine. New England Journal of Medicine 2020;383(27):2603-2615. DOI: 10.1056/NEJMoa2034577.

56. $\mathrm{Yu}$ J, Tostanoski LH, Peter $\mathrm{L}$, et al. DNA vaccine protection against SARS-CoV-2 in rhesus macaques. Science 2020;369(6505):806-811. (In eng). DOI: 10.1126/science.abc6284.

57. Gao Q, Bao L, Mao H, et al. Development of an inactivated vaccine candidate for SARSCoV-2. Science 2020;369:77-81.

58. Pardi N, Hogan MJ, Porter FW, Weissman D. mRNA vaccines - a new era in vaccinology. Nat Rev Drug Discov 2018;17(4):261-279. (In eng). DOI: 10.1038/nrd.2017.243.

59. Cele S, Gazy I, Jackson L, et al. Escape of SARS-CoV-2 501Y.V2 from neutralization by convalescent plasma. Nature 2021;593(7857):142-146. DOI: 10.1038/s41586-02103471-w. 
638 60. Atyeo C, Fischinger S, Zohar T, et al. Distinct Early Serological Signatures Track with SARS-CoV-2 Survival. Immunity 2020;53(3):524-532.e4. DOI: https://doi.org/10.1016/i.immuni.2020.07.020.

61. Lee WS, Selva KJ, Davis SK, et al. Decay of Fc-dependent antibody functions after mild to moderate COVID-19. medRxiv 2020:2020.12.13.20248143. DOI: 10.1101/2020.12.13.20248143.

62. Winkler ES, Gilchuk P, Yu J, et al. Human neutralizing antibodies against SARS-CoV-2 require intact $\mathrm{Fc}$ effector functions for optimal therapeutic protection. Cell 2021;184(7):1804-1820.e16. DOI: https://doi.org/10.1016/i.cell.2021.02.026.

63. Chan CEZ, Seah SGK, Chye DH, et al. The Fc-mediated effector functions of a potent SARS-CoV-2 neutralizing antibody, SC31, isolated from an early convalescent COVID-19 patient, are essential for the optimal therapeutic efficacy of the antibody. bioRxiv 2020:2020.10.26.355107. DOI: 10.1101/2020.10.26.355107.

64. McMahan K, Yu J, Mercado NB, et al. Correlates of protection against SARS-CoV-2 in rhesus macaques. Nature 2021;590(7847):630-634. DOI: 10.1038/s41586-020-03041-6. 

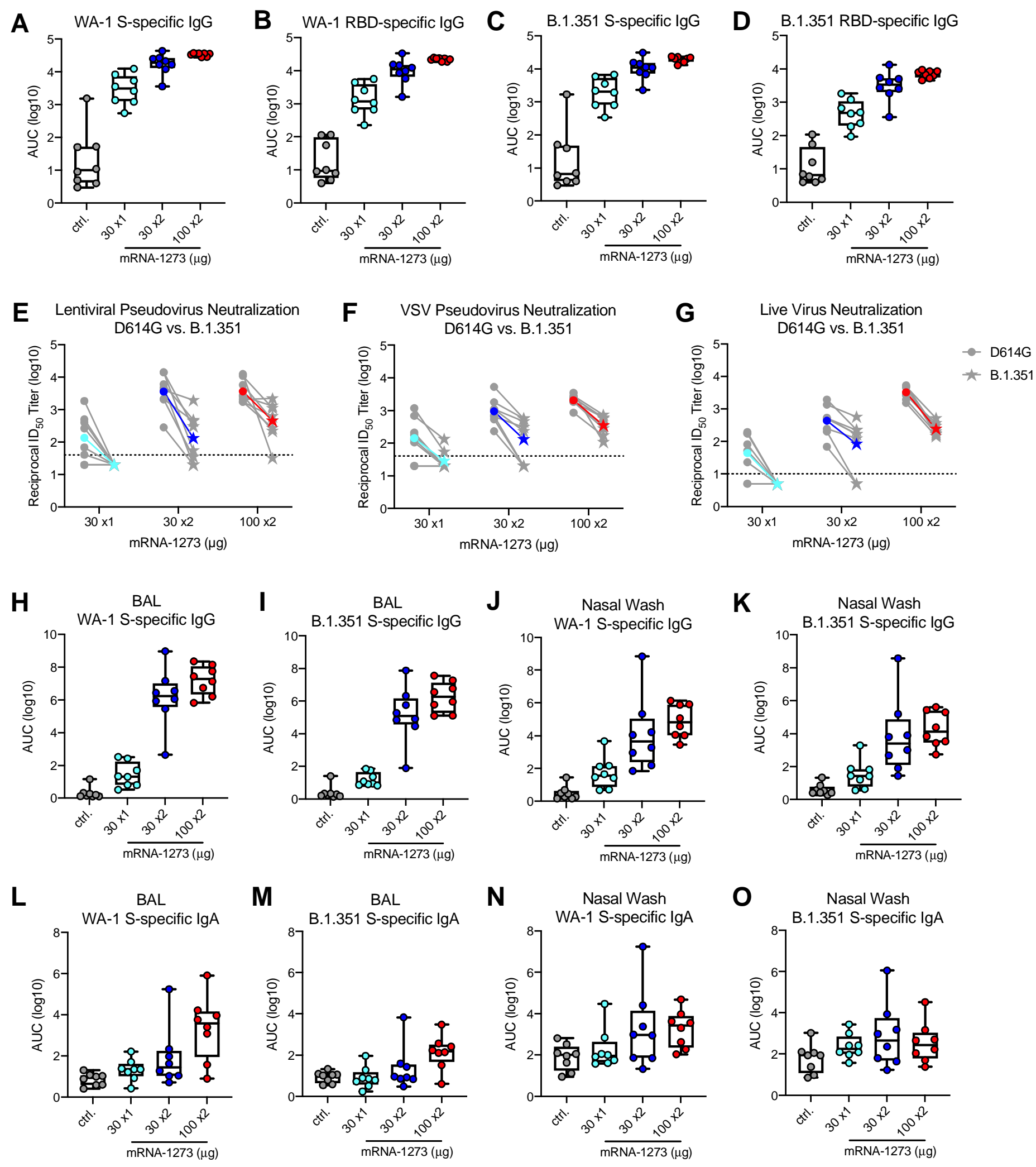

Figure 1. Antibody responses following mRNA-1273 immunization. Rhesus macaques were immunized with mRNA-1273 (30 $\mu \mathrm{g}$, one dose - light blue; $30 \mu \mathrm{g}$, two doses - dark blue; or $100 \mu \mathrm{g}$, two doses - red), according 
to Figure S1. Aged-matched naïve NHP (gray) were used as controls. Sera collected at week 12, immediately before challenge, were assessed for SARS-CoV-2 USA/Washington1 (WA-1) (A-B) and B.1.351 (C-D) Sspecific (A, C) and RBD-specific (B, D) IgG by MULTI-ARRAY ELISA, SARS-CoV-2 D614G and B.1.351 lentiviral-based pseudovirus neutralization (E), VSV-based pseudovirus neutralization (F), and focus reduction neutralization (G). BAL (H-I, L-M) and nasal washes (J-K, N-O) collected at week 7 were assessed for SARSCoV-2 WA-1 (H, J, L, N) and B.1.351 (I, K, M, O) S-specific IgG (H-K) and IgA (L-O) by MULTI-ARRAY ELISA. (A-D, H-O) Circles represent individual NHP. Boxes and horizontal bars denote the IQR and medians, respectively; whisker end points are equal to the maximum and minimum values. (E-G) Gray lines represent individual NHP, and colored lines represent geometric mean titers (GMT). Dotted lines indicate neutralization assay limits of detection. Symbols represent individual NHP and may overlap for equal values. 
Figure 2

A

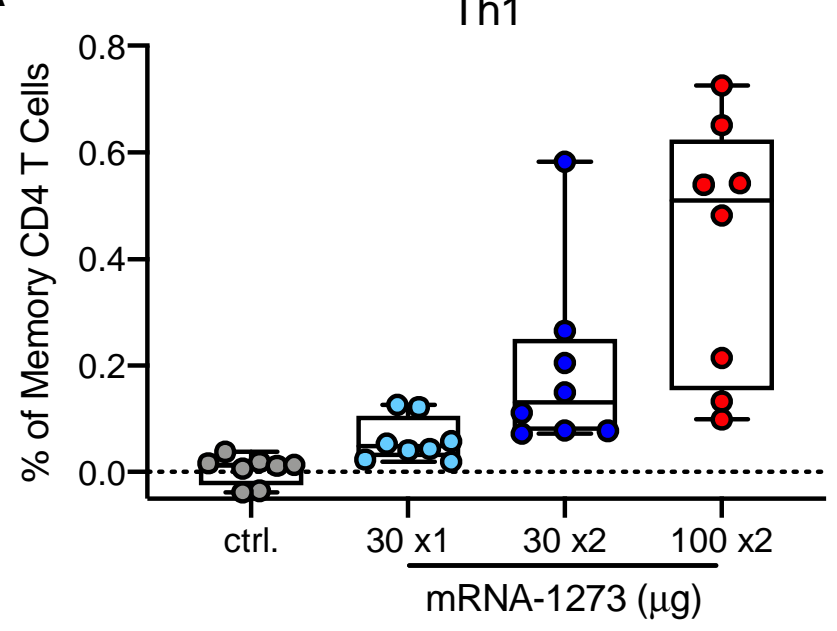

C

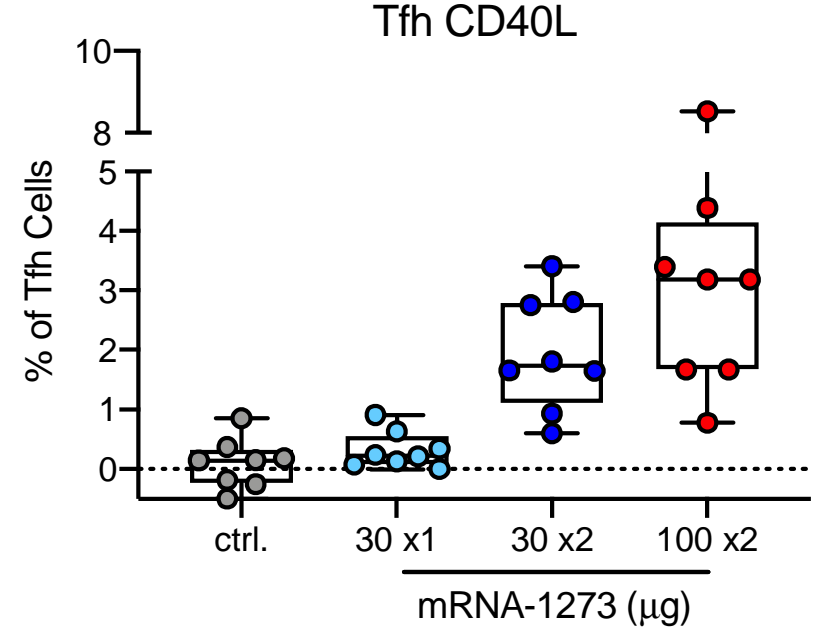

E

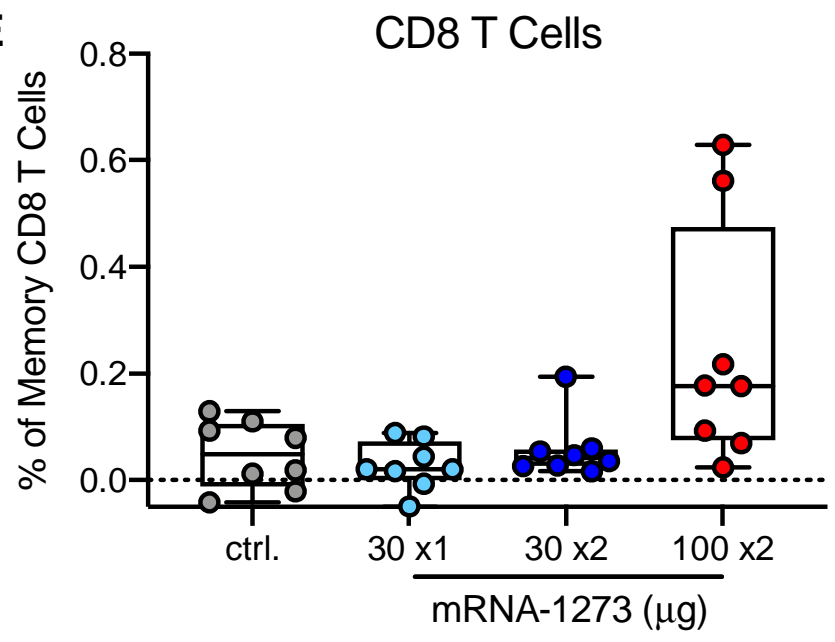

B

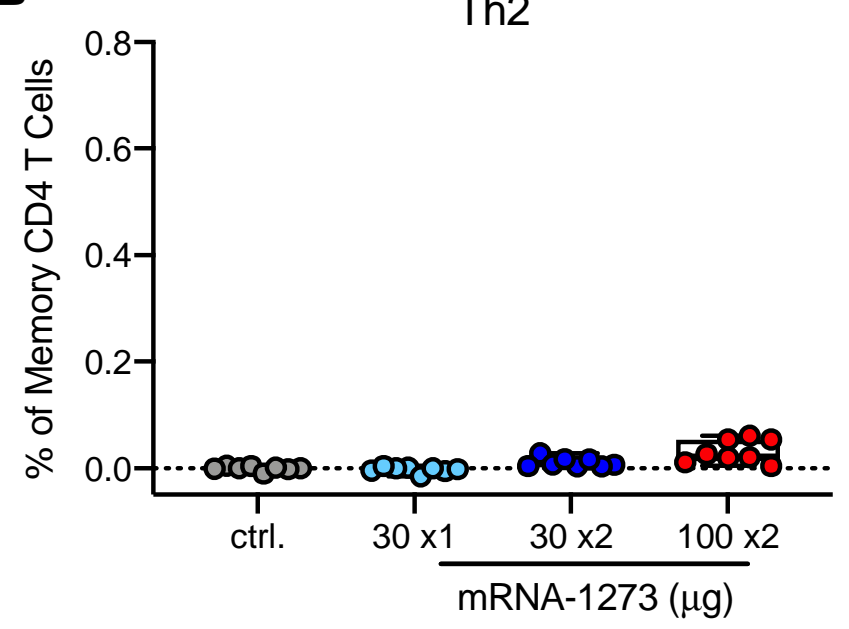

D

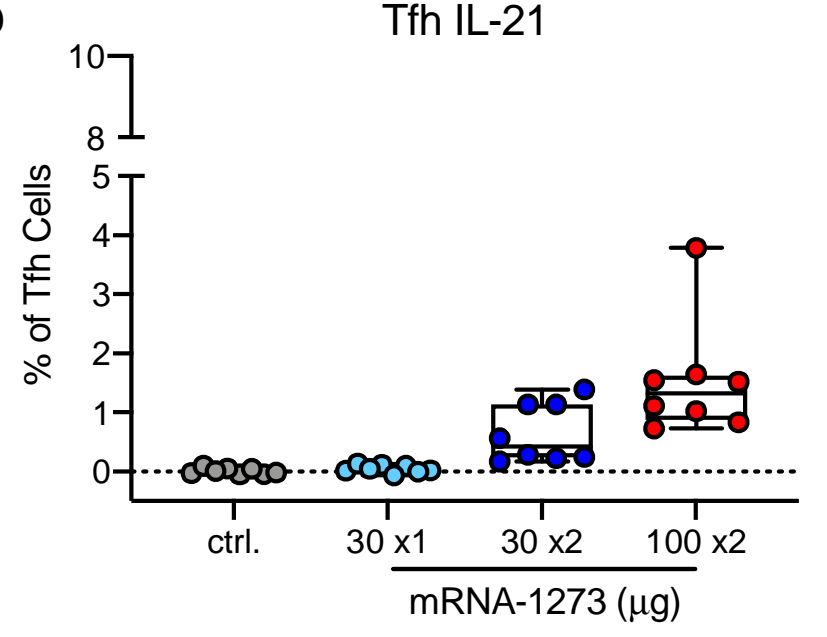

Figure 2. T cell responses following mRNA-1273 immunization. Rhesus macaques were immunized according to Figure S1. Intracellular staining was performed on PBMCs at week 7 to assess $\mathrm{T}$ cell responses to SARS-CoV-2 S protein peptide pools, S1 and S2. Responses to S1 and S2 individual peptide pools were summed. (A) Th1 responses (IFNg, IL-2, or TNF), (B) Th2 responses (IL-4 or IL-13), (C) Tfh CD40L 
upregulation (peripheral follicular helper $\mathrm{T}$ cells (Tfh) were gated on central memory $\mathrm{CXCR} 5^{+} \mathrm{PD}-$ $1^{+} \mathrm{ICOS}^{+} \mathrm{CD} 4 \mathrm{~T}$ cells), (D) Tfh IL-21, (E) CD8 T cells. Boxes and horizontal bars denote IQR and medians, respectively; whisker end points are equal to the maximum and minimum values. Circles represent individual NHP. Dotted lines are set to $0 \%$. 
A

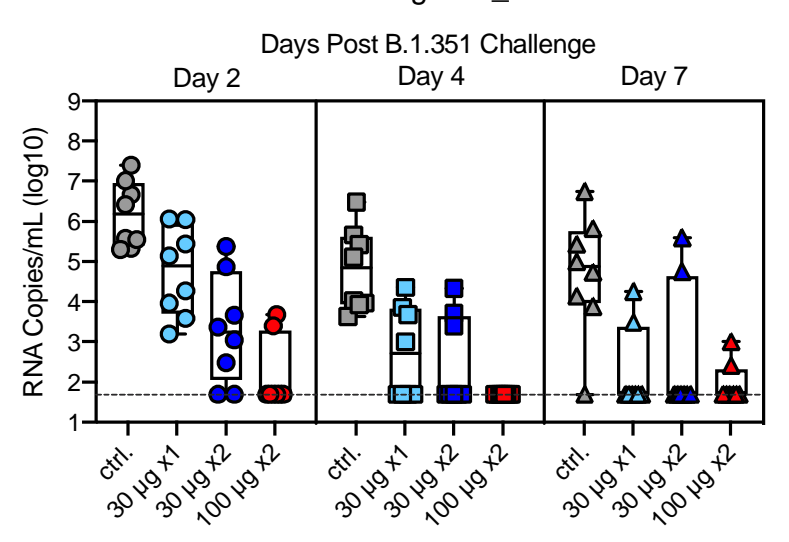

C

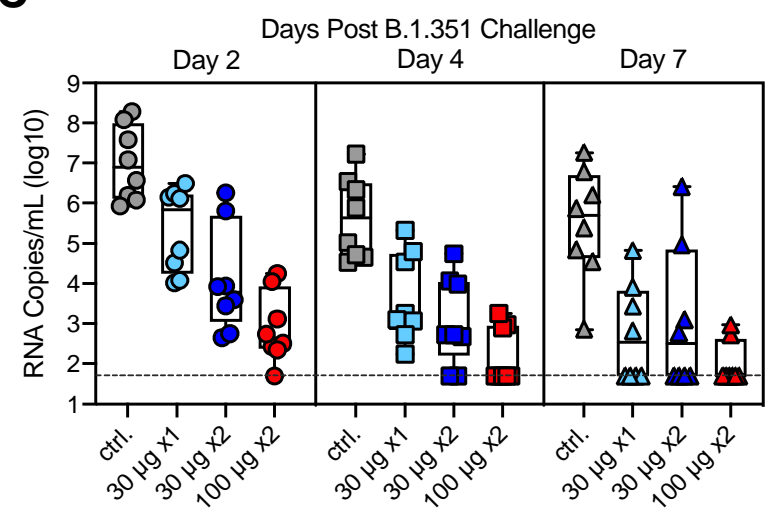

B

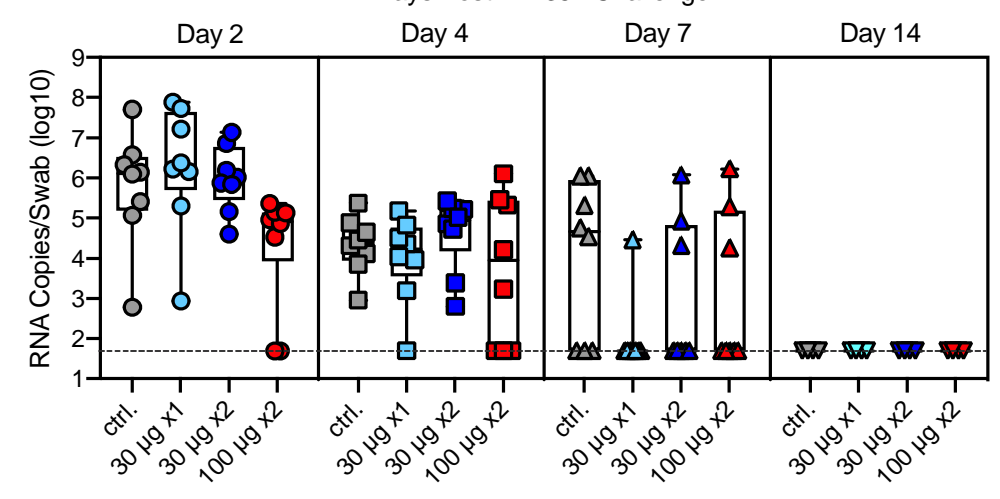

D

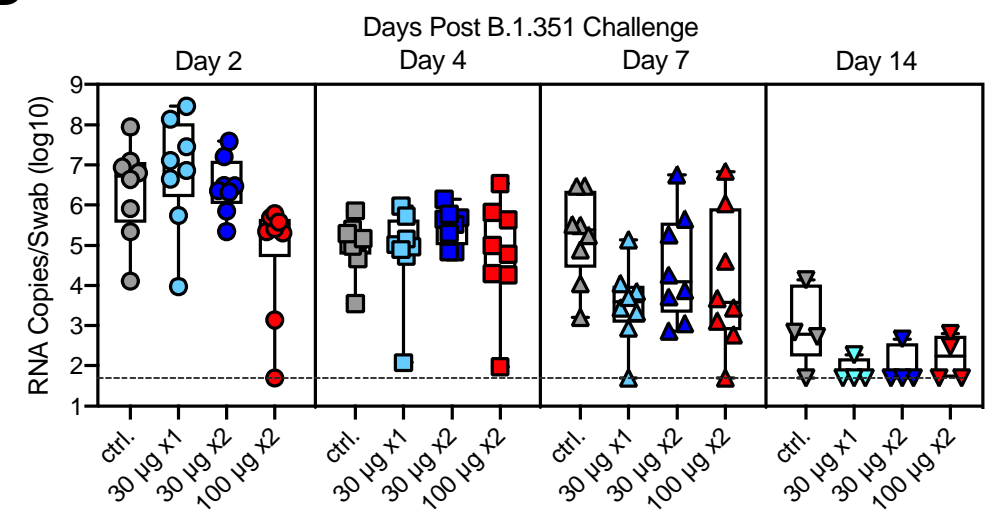

$\mathbf{E}$

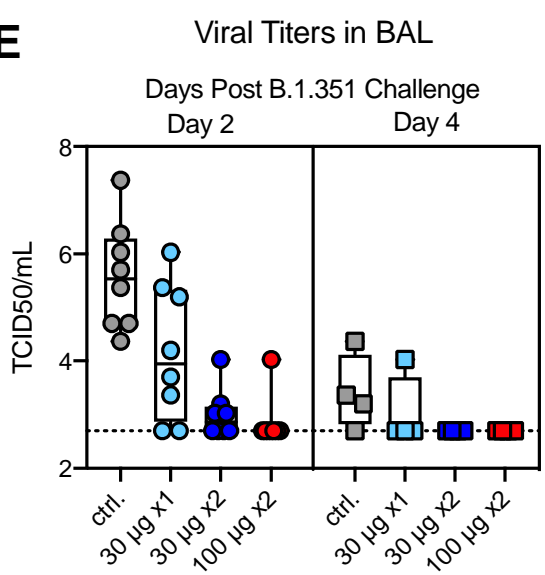

$\mathbf{F}$

BAL Viral Titer vs. BAL sgRNA_E
Day 2

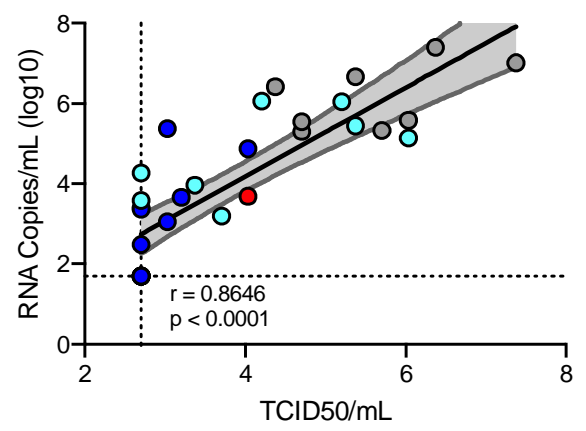

NS sgRNA_N

NS sgRNA_E

Days Post B.1.351 Challenge G BAL Viral Titer vs. BAL sgRNA_N
Day 2

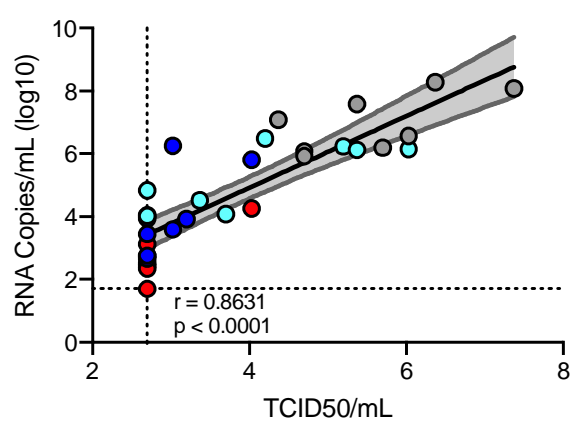

Figure 3. Efficacy of mRNA-1273 against upper and lower respiratory B.1.351 viral replication. Rhesus

macaques were immunized and challenged as described in Figure S1. BAL (A, C) and nasal swabs (NS) (B, D) were collected on days 2 (circles), 4 (squares), and 7 (triangles), and 14 (inverted triangles) post-challenge, where applicable, and viral replication was assessed by detection of SARS-CoV-2 E- (A-B) and N-specific (CD) sgRNA. (E) Viral titers were assessed by TCID50 assay for BAL collected on days 2 and 4 post-challenge. Boxes and horizontal bars denote the IQR and medians, respectively; whisker end points are equal to the 
Figure 3

maximum and minimum values. (F-G) Plots show correlations between viral titers and sgRNA_E (F) and sgRNA_N (G) in BAL 2 days post-challenge. Black and gray lines indicate linear regression and 95\% confidence interval, respectively. ' $r$ ' and 'p' represent Spearman's correlation coefficients and corresponding $p$ values, respectively. Symbols represent individual NHP and may overlap for equal values. 

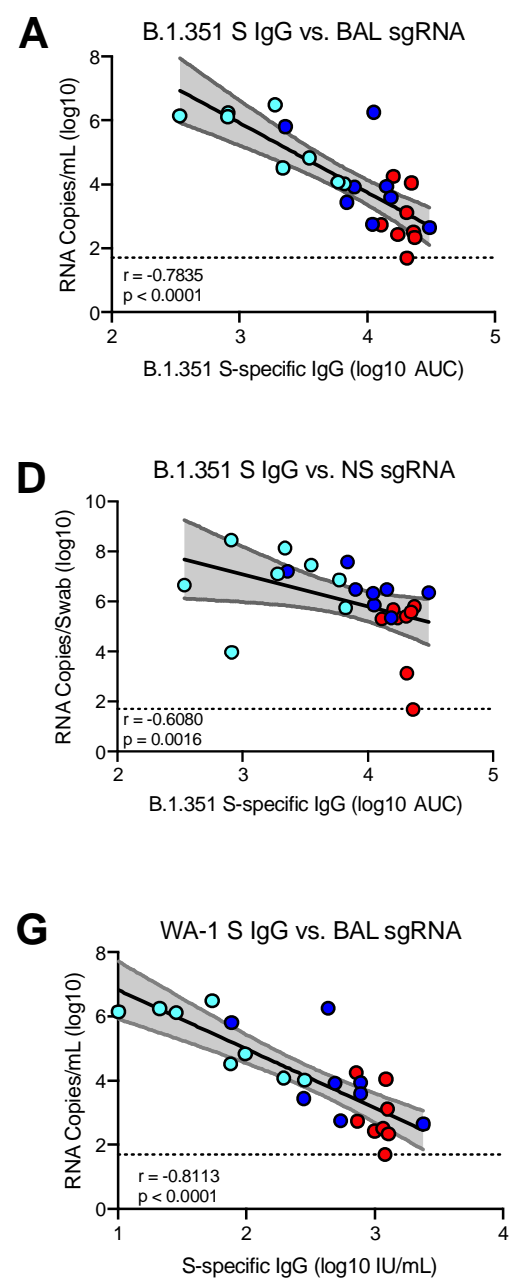
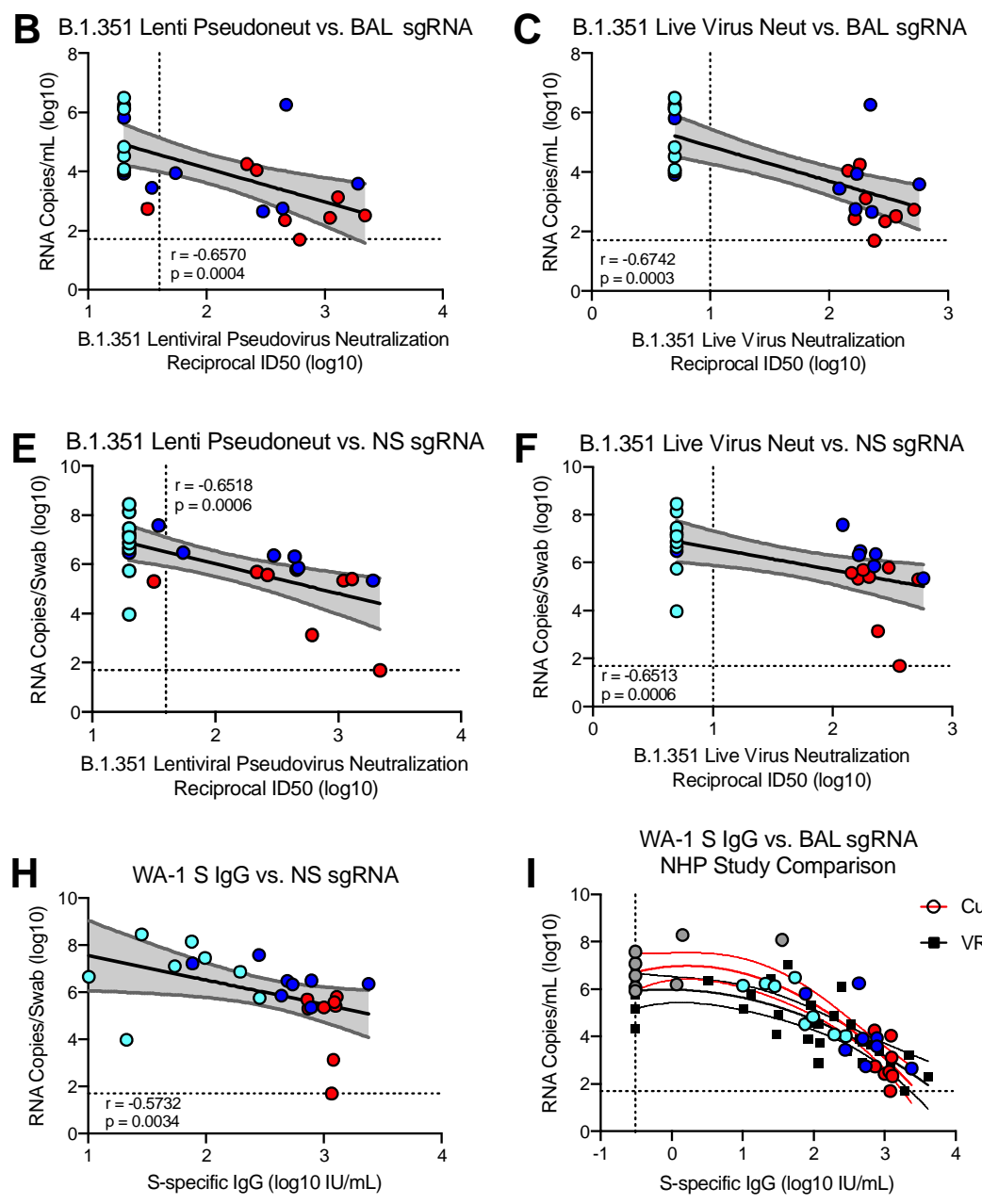

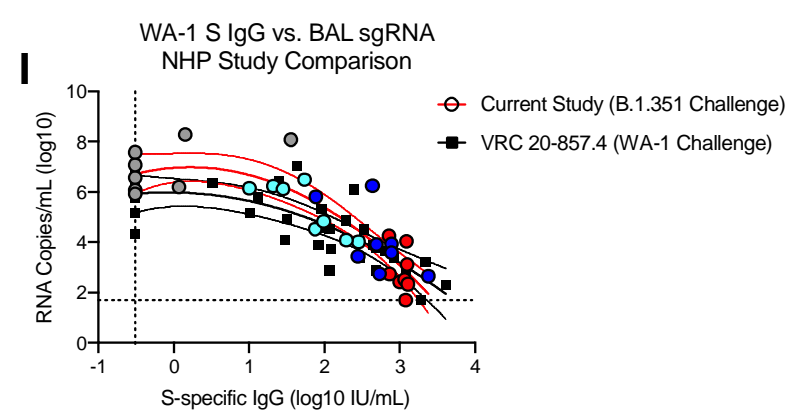

Figure 4. Antibody correlates of protection. Rhesus macaques were immunized and challenged as described in Figure S1. (A-F) Plots show correlations between week 12 SARS-CoV-2 B.1.351 S-specific IgG (A, D), lentiviral-based pseudovirus neutralization (B, E), and focus reduction neutralization $(\mathrm{C}, \mathrm{F})$ with $\mathrm{N}$-specific sgRNA in BAL (A-C) and NS (D-F) at day 2 post-challenge. (G-H) Plots show correlations between week 12 SARS-CoV-2 WA-1 S-specific IgG, converted to IU/mL, with N-specific sgRNA in BAL (G) and NS (H) at day 2 post-challenge. Circles represent individual NHP, where colors indicate mRNA-1273 dose. Dotted lines indicate assay limits of detection. (I) The relationship between pre-challenge WA-1 S-specific IgG and day 2 BAL sgRNA_N, with data from the current study using a B.1.351 challenge (filled circles, red curve fit) superimposed on data from our previous study with a WA-1 challenge (black squares, black curve fit); lines indicate quadratic curve fit and 95\% confidence intervals. Symbols represent individual NHP and may overlap for equal values. 